\title{
The Effect of Fe Doping on the Magnetic and Magnetocaloric Properties of $\mathbf{M n}_{5-x} \mathbf{F e}_{x} \mathbf{G e}_{3}$
}

\author{
Jeffrey Brock, Nathanael Bell-Pactat, Hong Cai, Timothy Dennison, \\ Tucker Fox, Brandon Free, Rami Mahyub, Austin Nar, Michael Saaranen, \\ Tiago Schaeffer, and Mahmud Khan
}

Department of Physics, Miami University, Oxford, OH 45056, USA

Correspondence should be addressed to Mahmud Khan; khanm2@miamioh.edu

Received 18 January 2017; Revised 17 February 2017; Accepted 23 February 2017; Published 6 March 2017

Academic Editor: Jamal Berakdar

Copyright (c) 2017 Jeffrey Brock et al. This is an open access article distributed under the Creative Commons Attribution License, which permits unrestricted use, distribution, and reproduction in any medium, provided the original work is properly cited.

\begin{abstract}
The magnetic and magnetocaloric properties of a series of minutely doped $\mathrm{Mn}_{5-x} \mathrm{Fe}_{x} \mathrm{Ge}_{3}$ compounds that exhibit the $\mathrm{D} 8_{8}$-type hexagonal crystal structure at room temperature have been investigated. For all Fe concentrations, the alloys are ferromagnetic and undergo a second-order ferromagnetic-to-paramagnetic transition near room temperature. Although the small Fe doping had little effect on the ferromagnetic transition temperatures of the system, changes in the saturation magnetization and magnetic anisotropy were observed. For $x \leq 0.15$, all compounds exhibit nearly the same magnetic entropy change of $\sim 7 \mathrm{~J} / \mathrm{kg} \mathrm{K}$, for a field change of $50 \mathrm{kOe}$. However, the magnitude of the refrigerant capacities increased with Fe doping, with values up to $108.5 \mathrm{~J} / \mathrm{kg}$ and $312 \mathrm{~J} / \mathrm{kg}$ being observed for field changes of $20 \mathrm{kOe}$ and $50 \mathrm{kOe}$, respectively. As second-order phase transition materials, the $\mathrm{Mn}_{5-x} \mathrm{Fe}_{x} \mathrm{Ge}_{3}$ compounds are not subject to the various drawbacks associated with first-order phase transition materials yet exhibit favorable magnetocaloric effects.
\end{abstract}

\section{Introduction}

Motivated by the energy-inefficiency, environmental impacts, and poor durability of current gas-compression based refrigeration technologies, there has been a great deal of interest in the development of alternative technologies that are more energy efficient and environmentally friendly. One such solution that has spurred considerable interest is the magnetocaloric effect (MCE) $[1,2]$. In brief, the MCE occurs when a magnetic material is adiabatically magnetized in a changing magnetic field. As the individual magnetic moments align themselves with the applied field, there is a decrease in the number of energy microstates available to the system, commensurate to an isothermal magnetic entropy change $\left(\Delta S_{M}\right)$. This change in a thermodynamic state variable can lead to an adiabatic temperature change $\left(\Delta T_{\mathrm{Ad}}\right)$. The $\Delta T_{\mathrm{Ad}}$ generated via the MCE can enable the transport of a significant amount of heat at greater efficiency than current technologies, attracting interest for solid-state cooling applications [3]. First observed in Ni by Weiss in 1917, research interest in MCE burgeoned after Pecharsky and Gschneidner Jr. published their seminal report regarding so-called giant MCE in $\mathrm{Gd}_{5}\left(\mathrm{Si}_{2} \mathrm{Ge}_{2}\right)$, attainable using magnetic field changes within the reach of permanent magnets [4].

Generally, large MCE is associated with materials that undergo a coupled first-order magnetostructural phase transition (FOMPT), as the simultaneous change in both the magnetic and structural phase is conducive to larger $\Delta S_{M}$ values and potentially larger $\Delta T_{\mathrm{Ad}}$ values [5-7]. Strong MCE has been observed in many Mn-based FOMPT materials, including $\mathrm{MnFe}(\mathrm{P}, \mathrm{As})$ [3, 8-10], $\mathrm{Mn}(\mathrm{As}, \mathrm{Sb})$ [5], and $\mathrm{MnFe}(\mathrm{P}, \mathrm{As}, \mathrm{Ge})$ [11] compounds. Unfortunately, the heightened MCE of these materials is offset by the downfalls that all FOMPT materials are susceptible to, including thermal and magnetic hysteresis losses and irreproducibility due to mechanical fatigue [12]. Moving towards the realization of robust magnetic refrigeration technologies, it is clear that these FOMPT pitfalls should be addressed in FOMPT materials, or that FOMPT-comparable MCE should be sourced from materials exhibiting second-order phase transitions. 
The $\mathrm{Mn}_{5} \mathrm{Ge}_{3}$ compound has attracted significant research interest because it exhibits a second-order ferromagnetic phase transition with a Curie temperature $\left(T_{C}\right)$ near room temperature $(296 \mathrm{~K})$ in addition to a moderately large $\Delta S_{M}$ $(9.2 \mathrm{~J} / \mathrm{kg} \mathrm{K}$ for a field change of $50 \mathrm{kOe})[13,14]$; both of these quantities are characteristics that should be sought from candidate MCE materials. Given that the magnetic properties of transition metal-based systems are heavily sensitive to the interatomic distances that governs the magnetic exchange mechanisms $[15,16]$, attempts have been made to incorporate other transition metals within basic systems in order to modify the lattice parameters and exchange interactions and thus optimize the magnetic and MCE properties of the $\mathrm{Mn}_{5} \mathrm{Ge}_{3}$ parent compound [15]. One such system is the $\mathrm{Mn}_{5-x} \mathrm{Fe}_{x} \mathrm{Ge}_{3}$ series previously investigated by Zhang et al. [17]. In their report, they employed substitutions with $x$ ranging from 0 to 1 , in steps of 0.25 , and found that larger refrigerant capacities were observed in samples with smaller $x$ (less Fe). This system is worth reexamination using smaller substitutions, given that the previously reported replacements displaced $T_{C}$ from $300 \mathrm{~K}$ in the $x=0$ compound to $330 \mathrm{~K}$ in the $x=1$ compound, as well as the aforementioned findings regarding the refrigerant capacity.

Keeping this in mind, we have performed an experimental study of the $\mathrm{Mn}_{5-x} \mathrm{Fe}_{x} \mathrm{Ge}_{3}(0 \leq x \leq 0.15)$ system, exploring the effect of smaller Fe substitutions on the structural, magnetic, and magnetocaloric properties of the compounds. In limiting investigation to small substitutions of Fe, our goals were to observe whether a changing nature of the magnetic interactions was apparent across the series and to assess the MCE potential of the compounds by means of $\Delta S_{M}$ and refrigerant capacity calculations.

\section{Experimental Details}

Polycrystalline buttons of $\mathrm{Mn}_{5-x} \mathrm{Fe}_{x} \mathrm{Ge}_{3}(0 \leq x \leq 0.15)$ weighing approximately $2 \mathrm{~g}$ each were fabricated in Ar atmosphere using the vacuum arc melting technique. The virgin metals used in fabrication were of at least $3 \mathrm{~N}$ purity, and an additional $2 \mathrm{wt} . \%$ of $\mathrm{Mn}$ was incorporated to account for $\mathrm{Mn}$ loss during the melting process. The samples were flipped and remelted several times in order to ensure homogeneity. Next, the as-casted buttons were wrapped in Ta foil, sealed in partially evacuated (Ar partial pressure) vycor tubes, and annealed at $750^{\circ} \mathrm{C}$ for four days in an electric furnace to promote further homogenization. After annealing, the samples were immediately quenched in cold water.

In order to explore the structure and phase purity of the alloys, powder X-ray diffraction (XRD) measurements were performed using a Scintag PAD X, a device which employs a monochromatic $\mathrm{Cu}-\mathrm{K} \alpha_{1}$ radiation source and a thetatheta geometry. The powder patterns were indexed using PowderCell [18]. Compositional properties were examined using a Zeiss Supra 35 FEG SEM, equipped with energydispersive X-ray spectroscopic (EDS) capabilities. Magnetization as a function of temperature and applied magnetic field $(M(T)$ and $M(H)$, resp.) were measured using a Physical Property Measurement System (PPMS), manufactured by Quantum Design, Inc. $M(T)$ and $M(H)$ measurements were

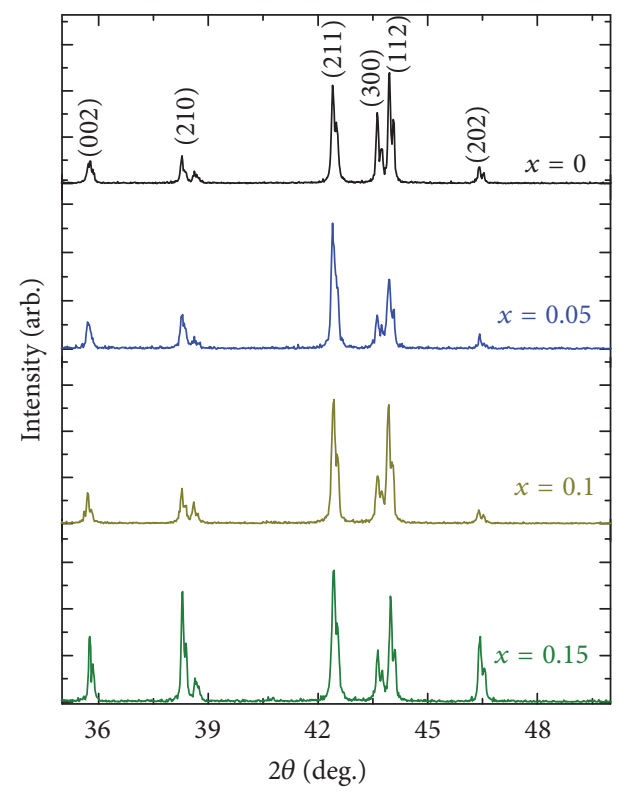

FIGURE 1: Room temperature XRD patterns for the $\mathrm{Mn}_{5-x} \mathrm{Fe}_{x} \mathrm{Ge}_{3}$ system.

performed in temperatures ranging from 5 to $400 \mathrm{~K}$ and in applied magnetic fields up to $50 \mathrm{kOe} . M(T)$ data was collected under both the zero-field-cooled and field-cooled protocols (ZFC and FC, resp.), and each sample's $T_{C}$ was determined by inspecting the derivative of the $M(T)$ curves for the minima. From $M(H)$ measurements collected isothermally at temperatures near the samples' $T_{C}, \Delta S_{M}$ was determined using the well-known Maxwell relation [19]:

$$
\Delta S_{M}=-\int_{0}^{H}\left(\frac{\partial M}{\partial T}\right)_{H} d H .
$$

Furthermore, as $\Delta S_{M}$ may not necessarily be the best metric by which to judge the appropriateness of a material for MCE applications, we have calculated the refrigerant capacity (RC) of our compounds using the $\mathrm{RC}_{A}$ expression of Gschneidner and Pecharsky, given as follows [20]:

$$
\mathrm{RC}_{A}=\int_{T_{\text {Cold }}}^{T_{\text {Hot }}} \Delta S_{M}(T, \Delta H) d T,
$$

where $T_{\text {Hot }}$ and $T_{\text {Cold }}$ are defined as the temperature bounds forming the full-width at half-maximum of each sample's $\Delta S_{M}$ curve, for a given field change $(\Delta H)$.

\section{Results and Discussion}

The room temperature XRD patterns of the four fabricated $\mathrm{Mn}_{5-x} \mathrm{Fe}_{x} \mathrm{Ge}_{3}$ compounds are shown in Figure 1. In agreement with previous literature on the $\mathrm{Mn}_{5-x} \mathrm{Fe}_{x} \mathrm{Ge}_{3}$ system, the compounds were found to crystallize in the hexagonal D8 $8_{8}$-type crystalline structure (CSG: $\mathrm{P} 63 / \mathrm{mcm}$ ). The lattice parameters of the $x=0$ sample and all samples' $c / a$ ratios match the literature as well. Rietveld refinement of the powder patterns corroborates past neutron diffraction studies 

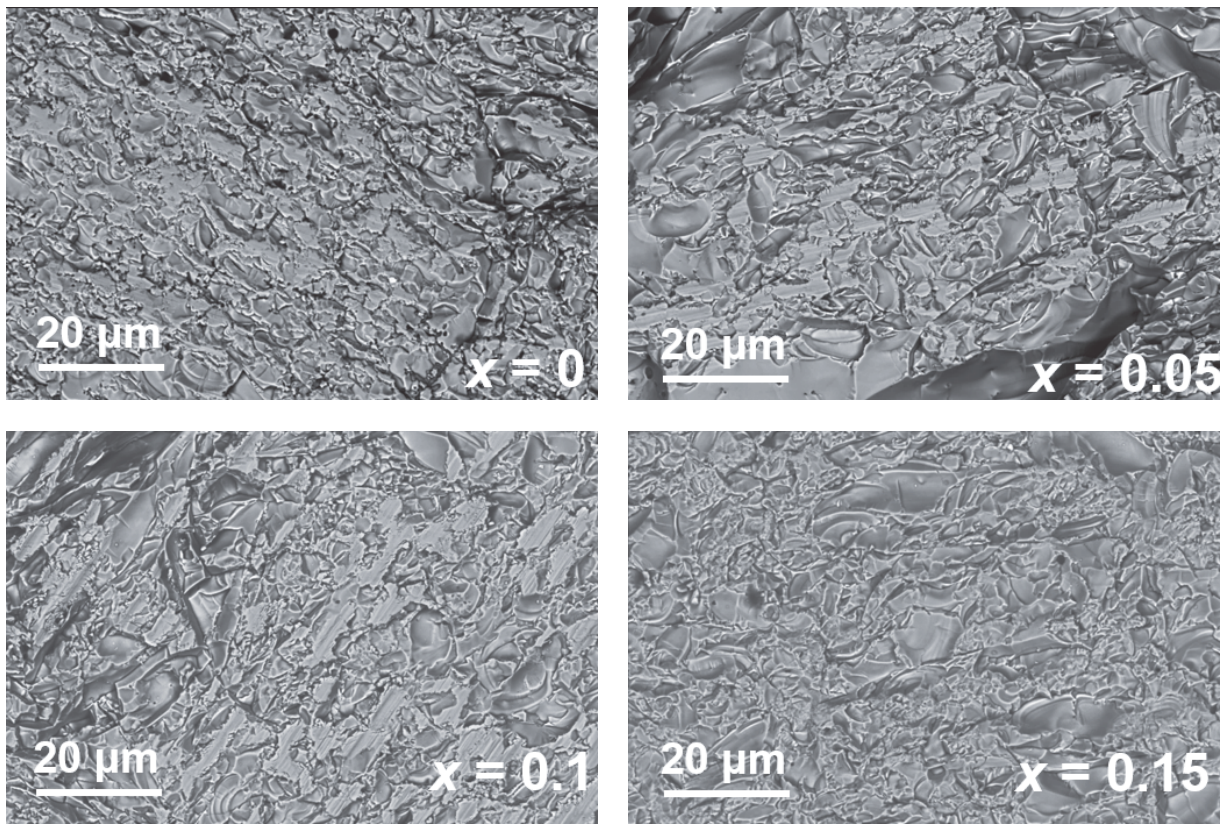

FIGURE 2: Backscatter SEM micrographs of the $\mathrm{Mn}_{5-x} \mathrm{Fe}_{x} \mathrm{Ge}_{3}$ compounds, collected using a $30 \mathrm{keV}$ primary beam.

of the $\mathrm{Mn}_{5} \mathrm{Ge}_{3}$ compound, suggesting that Mn occupies the $4 d$ and $6 g$ crystallographic sites while Ge is localized to the $6 f$ sites [24]. The lattice parameters decrease minutely with $x$, from $a=b=7.2058 \AA$ and $c=5.0398 \AA$ in the $x=0$ sample to $a=b=7.2023 \AA$ and $c=5.0375 \AA$ in the $x=0.15$ sample. The static $c / a$ ratio across the system indicates a uniform cell contraction, suggesting that the substitutional Fe assumes the $4 d$ site in $\mathrm{Mn}_{5-x} \mathrm{Fe}_{x} \mathrm{Ge}_{3}$. SEM backscatter micrographs of the compounds are shown in Figure 2. The lack of contrast in the micrographs demonstrates that a single compositional phase is formed in the $\mathrm{Mn}_{5-x} \mathrm{Fe}_{x} \mathrm{Ge}_{3}$ compounds, suggesting that a nearly ideal solid-state solution is formed. EDS analysis (not shown) showed that the fabricated alloys suitably matched their respective targeted compositions.

The $M(T)$ data for the $\mathrm{Mn}_{5-x} \mathrm{Fe}_{x} \mathrm{Ge}_{3}$ compounds is shown in Figure 3 . The $M(T)$ curves were collected in a $1 \mathrm{kOe}$ magnetic field. For each sample, the only anomalous behavior observed is the sudden drop in magnetization corresponding to the ferromagnetic-to-paramagnetic phase transition at $T_{C}$. The lack of thermal hysteresis at the phase transition between the ZFC and FC curves indicates that it is a second-order transition. Interestingly, $T_{C}$ is nearly constant across the series ( $296 \mathrm{~K})$. It was previously argued that $\mathrm{Fe}$ and $\mathrm{Mn}$ randomly occupy the $4 d$ sites in $\mathrm{Mn}_{5-x} \mathrm{Fe}_{x} \mathrm{Ge}_{3}$ compounds [17]. It is possible that the maximum concentration of $\mathrm{Fe}(x \leq 0.15$, where 0.15 implies only 3 at. \%) in our compounds is not large enough to cause any change in the exchange interactions, as far as $T_{C}$ is concerned.

To further explore the magnetic properties of the $\mathrm{Mn}_{5-x} \mathrm{Fe}_{x} \mathrm{Ge}_{3}$ compounds, $M(H)$ curves were collected at $T=10 \mathrm{~K}$ and the results are shown in Figure 4. As shown in the figure, all samples exhibit typical ferromagnetic behavior and attain magnetic saturation $\left(M_{S}\right)$ well below $50 \mathrm{kOe}$. As shown in the inset of Figure $4, M_{S}$ initially increases with $x$ until $x=0.05$ and decreases with further increase of $x$. The initial increase in $M_{S}$ may be attributed to the occupancy considerations discussed above as well as the comparatively larger magnetic moment of the $\mathrm{Fe}$ atoms versus the $4 d$ Mn atoms $\left(2.6 \mu_{\mathrm{B}}\right.$ to $1.85 \mu_{\mathrm{B}}$, resp.) [25]. The decreased $M_{S}$ in the higher-Fe samples may be explained by an appeal to the XRD findings, which demonstrated a uniform unit cell contraction with Fe content. As the lattice parameters decrease, it is possible that the ferrimagnetic ordering of the $\mathrm{Fe}_{5} \mathrm{Ge}_{3}$ phase may become more dominant in determining the bulk magnetic properties of the $\mathrm{Mn}_{5-x} \mathrm{Fe}_{x} \mathrm{Ge}_{3}$ compounds [17]. Additionally, it is noted that the $M(H)$ curves for samples with $x \leq 0.1$ exhibit relatively "harder" magnetic behavior, whereas the samples with $x>0.1$ exhibit "softer" magnetic behavior [26]. This indicates that a greater degree of magnetic anisotropy exists in the higher-Fe samples and further confirms a change in magnetic properties across the relatively small compositional span of the $\mathrm{Mn}_{5-x} \mathrm{Fe}_{x} \mathrm{Ge}_{3}(0 \leq$ $x \leq 0.15)$ system.

In order to assess the magnetic entropy changes $\left(\Delta S_{M}\right)$ in the $\mathrm{Mn}_{5-x} \mathrm{Fe}_{x} \mathrm{Ge}_{3}$ compounds, isothermal $M(H)$ data was collected at multiple temperatures in the vicinity of the samples' $T_{C}$. As an illustration, isothermal $M(H)$ data for the $x=0.05$ compound is shown in Figure 5. It is clear that the sample with $x=0.05$ exhibits typical ferromagnetic behavior (i.e., paramagnetic for isotherms above $T_{C}$, ferromagnetic below $T_{C}$ [27]). From each sample's isothermal $M(H)$ curves, the respective $\Delta S_{M}(T)$ curve was determined by applying (1) to each of the five field changes, and the results are shown in Figure 6. It is evident that $\Delta S_{M}(T)$ initially increases with temperature until each sample's respective $T_{C}$, at which point it begins to decay. The largest peak $\Delta S_{M}$ values are observed in the sample with $x=0-7.0 \mathrm{~J} / \mathrm{kg} \mathrm{K}$ and $3.65 \mathrm{~J} / \mathrm{kg} \mathrm{K}$ for field changes of $50 \mathrm{kOe}$ and $20 \mathrm{kOe}$, respectively. 

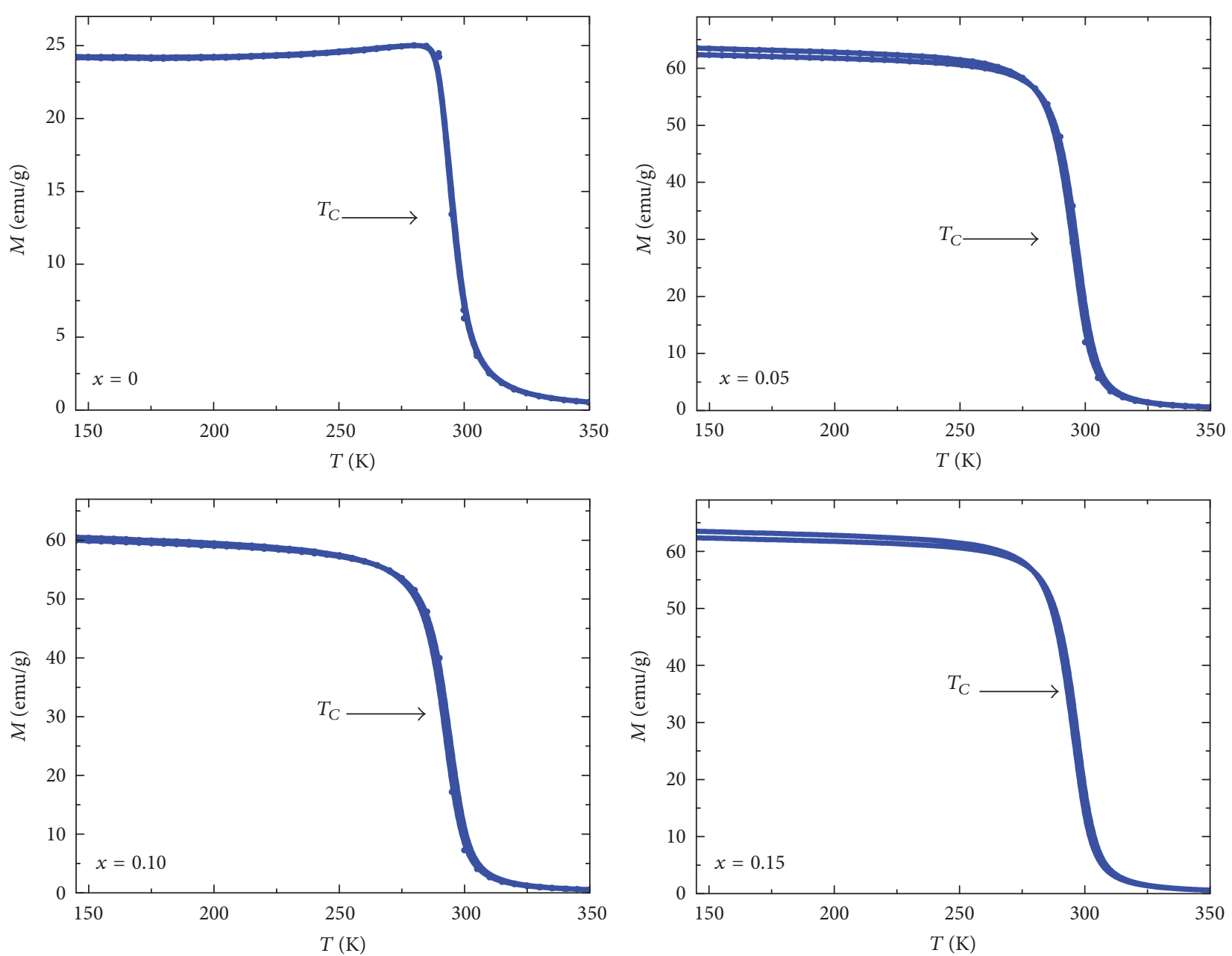

FIgURE 3: Temperature dependence of magnetization, $M(T)$, for the $\mathrm{Mn}_{5-x} \mathrm{Fe}_{x} \mathrm{Ge}_{3}$ system. The data was collected in an applied magnetic field of $1 \mathrm{kOe}$.

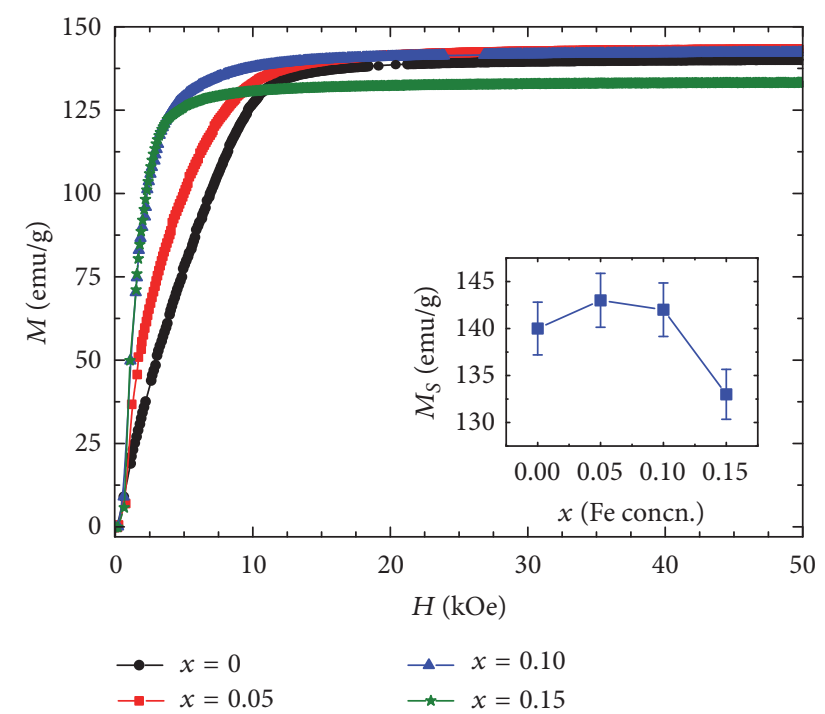

FIGURE 4: Magnetization as a function of applied magnetic field, $M(H)$, for the $\mathrm{Mn}_{5-x} \mathrm{Fe}_{x} \mathrm{Ge}_{3}$ system, measured at a temperature of $10 \mathrm{~K}$. The inset shows the saturation magnetization, $M_{S}$, as a function of Fe concentration.

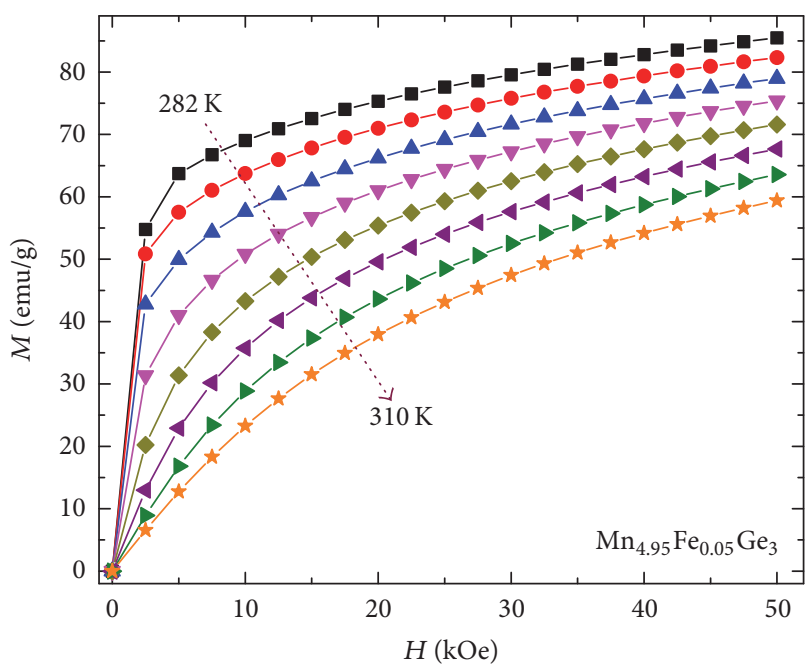

FIGURE 5: Isothermal magnetization as a function of applied magnetic field of the $\mathrm{Mn}_{5-x} \mathrm{Fe}_{x} \mathrm{Ge}_{3}(x=0.05)$ sample measured at isotherms in the vicinity of the sample's Curie temperature.

As mentioned earlier, the peak $\Delta S_{M}$ values are not the only or most appropriate quantity by which to judge the 


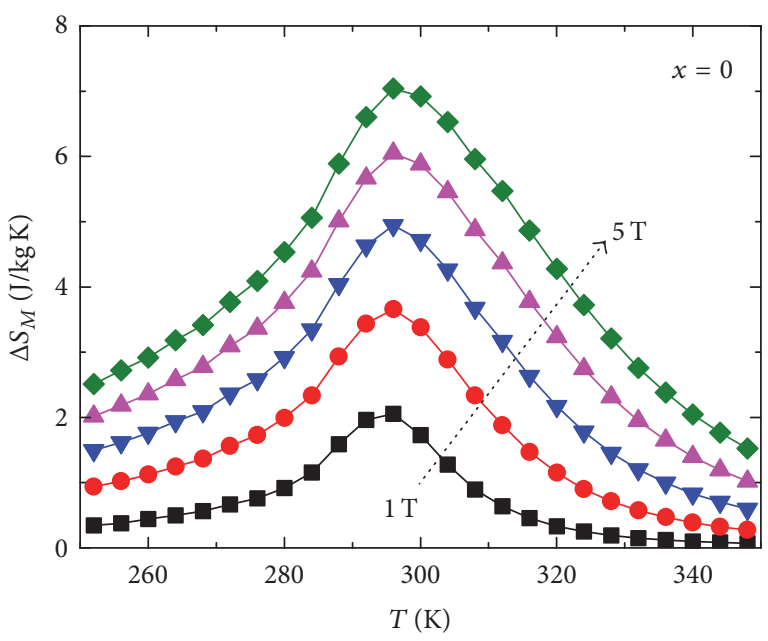

(a)

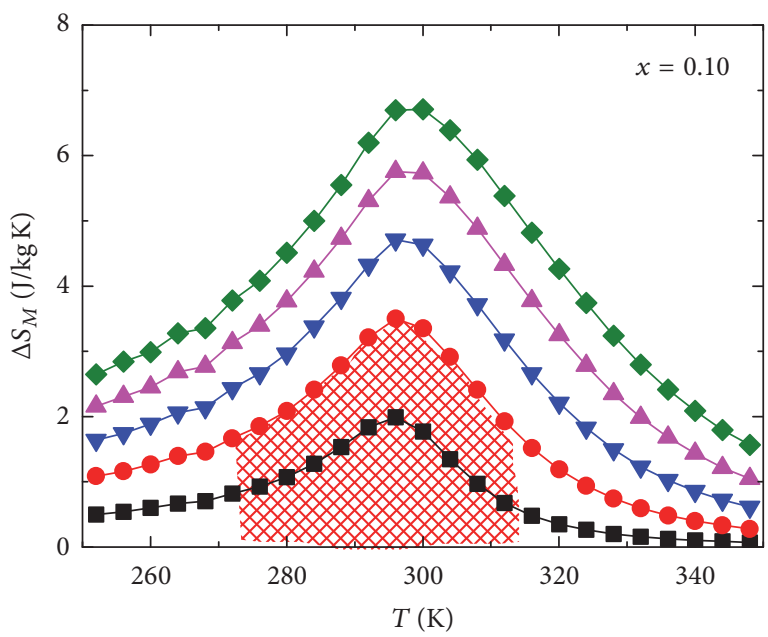

(c)

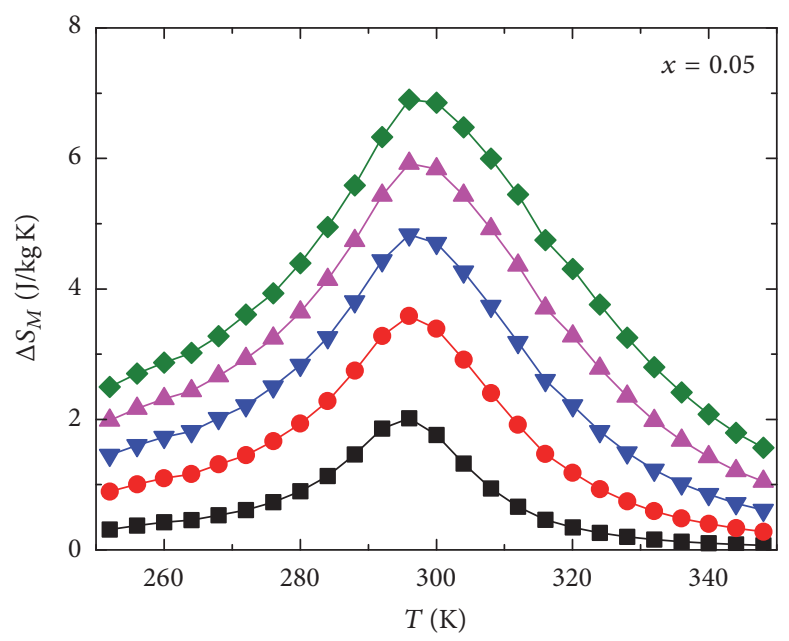

(b)

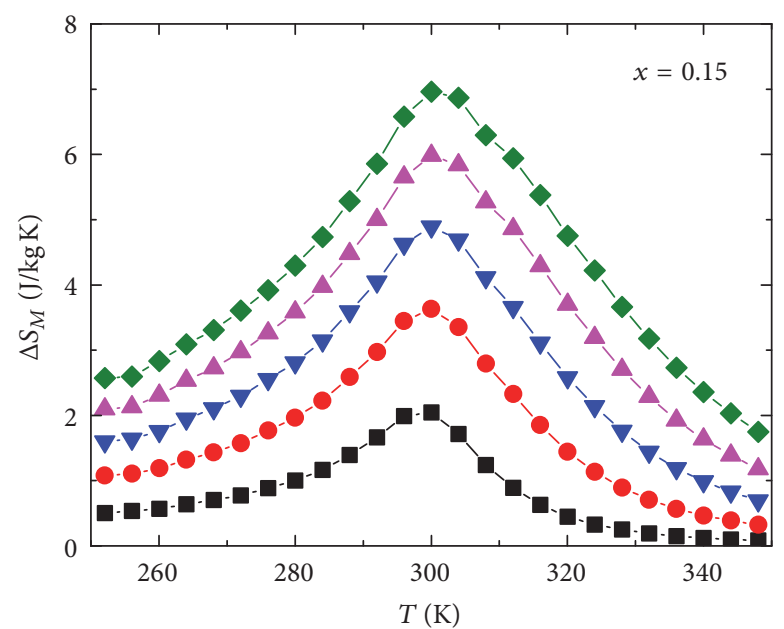

(d)

FIgURE 6: The magnetic entropy change as a function of temperature of the $\mathrm{Mn}_{5-x} \mathrm{Fe}_{x} \mathrm{Ge}_{3}$ compounds, for magnetic field changes of $10 \mathrm{kOe}$ (1 T) to $50 \mathrm{kOe}(5 \mathrm{~T})$.

MCE potential of a material. Using the well-established protocol enumerated in (2), we calculated each sample's $\mathrm{RC}_{A}$ for the explored field changes, and the results are shown in Table 1. A visual representation of this integration for a field change of $20 \mathrm{kOe}$ is provided in Figure 6(c) for the $x=0.1$ sample. From Table 1 , it is apparent that the $x=$ 0.15 sample exhibits the largest $\mathrm{RC}_{A}$ values $-108.5 \mathrm{~J} / \mathrm{kg}$ and $312 \mathrm{~J} / \mathrm{kg}$ for field changes of $20 \mathrm{kOe}$ and $50 \mathrm{kOe}$, respectively. The heightened MCE properties of the $x=0.15$ sample may be explained by the broadness of its $\Delta S_{M}$ full-width at half-maximum. While the RC values reported in [17] were calculated using the Wood/Potter technique, recent literature overwhelmingly utilizes $\mathrm{RC}_{A}$ as the MCE assessment parameter; thus, we have chosen to use this metric as it is more suitable for comparison. The $\mathrm{RC}_{A}$ values calculated for the $\mathrm{Mn}_{5-x} \mathrm{Fe}_{x} \mathrm{Ge}_{3}(0 \leq x \leq 0.15)$ system favorably compare to a variety of recently reported second-order phase transition compounds, including $\mathrm{Mn}_{5} \mathrm{Ge}_{2.7} \mathrm{Ga}_{0.3}$ [21], $\mathrm{Mn}_{5} \mathrm{Ge}_{2.8} \mathrm{Sb}_{0.2}$ [13], $\mathrm{Gd}\left(\mathrm{Co}_{0.35} \mathrm{Mn}_{0.65}\right)_{2}$ [22], and $\mathrm{Ni}_{2} \mathrm{Mn}_{0.95} \mathrm{Cr}_{0.05}$ In [23], as demonstrated in Table 1. The large $\mathrm{RC}$ values of the $\mathrm{Mn}_{5-x} \mathrm{Fe}_{x} \mathrm{Ge}_{3}$ system suggest that it is worthy of further MCE explorations, including $\Delta T_{\mathrm{Ad}}$ measurements.

\section{Conclusion}

In brief, we have performed an experimental study of the structural, magnetic, and magnetocaloric properties of the $\mathrm{Mn}_{5-x} \mathrm{Fe}_{x} \mathrm{Ge}_{3}(0 \leq x \leq 0.15)$ system. All samples were found to crystallize in the $\mathrm{D} 8_{8}$-type hexagonal structure at room temperature and in a single compositional phase. Increasing Fe content has little effect on the Curie temperatures but has a noticeable effect on the saturation magnetization and magnetic anisotropy of the samples, indicating a change in the magnetic properties. For all Fe concentrations, large refrigerant capacities are observed in the vicinity of room temperature; maximal refrigerant capacities are observed in the sample with the highest $\mathrm{Fe} \mathrm{co}^{\mathrm{TM}}$ ntent, which has the magnetic anisotropy. The experimental findings 
TABLE 1: The magnetocaloric properties of the $\mathrm{Mn}_{5-x} \mathrm{Fe}_{x} \mathrm{Ge}_{3}$ compounds compared to several other second-order phase transition compounds.

\begin{tabular}{|c|c|c|c|c|c|}
\hline \multirow{2}{*}{ Compound } & \multicolumn{2}{|c|}{ Peak $\Delta S_{M}(\mathrm{~J} / \mathrm{kg} \mathrm{K})$} & \multicolumn{2}{|c|}{$\mathrm{RC}_{A}(\mathrm{~J} / \mathrm{kg})$} & \multirow{2}{*}{ Reference } \\
\hline & $20 \mathrm{kOe}$ & $50 \mathrm{kOe}$ & $20 \mathrm{kOe}$ & $50 \mathrm{kOe}$ & \\
\hline $\mathrm{Mn}_{5} \mathrm{Ge}_{3}$ & 3.65 & 7.0 & 97 & 298 & This work \\
\hline $\mathrm{Mn}_{4.95} \mathrm{Fe}_{0.05} \mathrm{Ge}_{3}$ & 3.58 & 6.9 & 95 & 294 & This work \\
\hline $\mathrm{Mn}_{4.9} \mathrm{Fe}_{0.1} \mathrm{Ge}_{3}$ & 3.50 & 6.96 & 104.5 & 305 & This work \\
\hline $\mathrm{Mn}_{4.85} \mathrm{Fe}_{0.15} \mathrm{Ge}_{3}$ & 3.63 & 6.9 & 108.50 & 312 & This work \\
\hline $\mathrm{Mn}_{5} \mathrm{Ge}_{2.7} \mathrm{Ga}_{0.3}$ & 3.2 & 6.1 & 84 & 256.2 & {$[21]$} \\
\hline $\mathrm{Mn}_{5} \mathrm{Ge}_{2.8} \mathrm{Sb}_{0.2}$ & - & 6.2 & - & 320 & {$[13]$} \\
\hline $\mathrm{Gd}\left(\mathrm{Co}_{0.35} \mathrm{Mn}_{0.65}\right)_{2}$ & - & 3.4 & - & 289 & {$[22]$} \\
\hline $\mathrm{Ni}_{2} \mathrm{Mn}_{0.95} \mathrm{Cr}_{0.05}$ In & 1.69 & 3.37 & 59.79 & 167.5 & {$[23]$} \\
\hline
\end{tabular}

suggest that additional magnetocaloric investigations of the $\mathrm{Mn}_{5-x} \mathrm{Fe}_{x} \mathrm{Ge}_{3}$ system may be warranted.

\section{Conflicts of Interest}

The authors declare that there is no conflicts of interest regarding the publication of this paper.

\section{Acknowledgments}

The XRD measurements were performed by Professor Shane Stadler's group at the Louisiana State University. The SEM micrographs and related EDS data were collected at the Miami University Center for Advanced Microscopy (CAMI), Oxford, OH 45056, USA.

\section{References}

[1] S. Ashley, "Fridge of the future," Mechanical Engineering, vol. 116, p. 76, 1994.

[2] C. Zimm, A. Jastrab, A. Sternberg et al., "Description and performance of a near-room temperature magnetic refrigerator," in Advances in Cryogenic Engineering, vol. 43 of Advances in Cryogenic Engineering, pp. 1759-1766, Springer, Berlin, Germany, 1998.

[3] E. Brück, M. Ilyn, A. Tishin, and O. Tegus, "Magnetocaloric effects in MnFeP1-xAsx-based compounds," Journal of Magnetism and Magnetic Materials, vol. 290-291, pp. 8-13, 2005.

[4] V. K. Pecharsky and K. A. Gschneidner Jr., "Giant magnetocaloric effect in $\mathrm{Gd}_{5}\left(\mathrm{Si}_{2} \mathrm{Ge}_{2}\right)$," Physical Review Letters, vol. 78, no. 23, pp. 4494-4497, 1997.

[5] H. Wada and Y. Tanabe, "Giant magnetocaloric effect of $\mathrm{MnAs}_{1-x} \mathrm{Sb}_{x}$," Applied Physics Letters, vol. 79, no. 20, 2001.

[6] O. Tegus, E. Brück, L. Zhang, Dagula, K. H. J. Buschow, and F. R. De Boer, "Magnetic-phase transitions and magnetocaloric effects," Physica B: Condensed Matter, vol. 319, no. 1-4, pp. 174192, 2002.

[7] F. Hu, B. Shen, J. Sun, Z. Cheng, G. Rao, and X. Zhang, "Influence of negative lattice expansion and metamagnetic transition on magnetic entropy change in the compound $\mathrm{LaFe}_{11.4} \mathrm{Si}_{1.6}$," Applied Physics Letters, vol. 78, no. 23, pp. 3675-3677, 2001.

[8] O. Tegus, E. Brück, K. H. J. Buschow, and F. R. De Boer, “Transition-metal-based magnetic refrigerants for room-temperature applications," Nature, vol. 415, no. 6868, pp. 150-152, 2002.
[9] O. Tegus, G. X. Lin, W. Dagula et al., "A model description of the first-order phase transition in $\mathrm{MnFeP}_{1-x} \mathrm{As}_{x}$," Journal of Magnetism and Magnetic Materials, vol. 290-291, pp. 658-660, 2005.

[10] E. Brück, O. Tegus, L. Zhang, X. W. Li, F. R. De Boer, and K. H. J. Buschow, "Magnetic refrigeration near room temperature with $\mathrm{Fe}_{2}$ P-based compounds," Journal of Alloys and Compounds, vol. 383, no. 1-2, pp. 32-36, 2004.

[11] O. Tegus, B. Fuquan, W. Dagula et al., "Magnetic-entropy change in $\mathrm{Mn}_{1.1} \mathrm{Fe}_{0.9} \mathrm{P}_{0.7} \mathrm{As}_{0.3--x} \mathrm{Ge}_{x}$," Journal of Alloys and Compounds, vol. 396, no. 1-2, pp. 6-9, 2005.

[12] E. Brück, "Developments in magnetocaloric refrigeration," Journal of Physics D: Applied Physics, vol. 38, no. 23, pp. R381-R391, 2005.

[13] Songlin, Dagula, O. Tegus, E. Brück, F. R. De Boer, and K. H. J. Buschow, "Magnetic and magnetocaloric properties of $\mathrm{Mn}_{5} \mathrm{Ge}_{3}{ }_{x} \mathrm{Sb}_{x}$," Journal of Alloys and Compounds, vol. 337, no. 1-2, pp. 269-271, 2002.

[14] T. Toliński and K. Synoradzki, "Specific heat and magnetocaloric effect of the $\mathrm{Mn}_{5} \mathrm{Ge}_{3}$ ferromagnet," Intermetallics, vol. 47, pp. 1-5, 2014.

[15] F. Q. Zhao, W. Dagula, O. Tegus, and K. H. J. Buschow, "Magnetic-entropy change in $\mathrm{Mn}_{5} \mathrm{Ge}_{3}{ }_{x} \mathrm{Si}_{x}$ alloys," Journal of Alloys and Compounds, vol. 416, no. 1-2, pp. 43-45, 2006.

[16] X. B. Liu and Z. Altounian, "Exchange interaction in $\mathrm{GdT}_{2}$ ( $\mathrm{T}=\mathrm{Fe}, \mathrm{Co}, \mathrm{Ni}$ ) from first-principles," Journal of Applied Physics, vol. 107, no. 9, 2010.

[17] Q. Zhang, J. Du, Y. B. Li et al., "Magnetic properties and enhanced magnetic refrigeration in $\left(\mathrm{Mn}_{1-x} \mathrm{Fe}_{x}\right)_{5} \mathrm{Ge}_{3}\left(\mathrm{Mn}_{1-x} \mathrm{Fe}_{x}\right)_{5} \mathrm{Ge}_{3}$ compounds," Journal of Applied Physics, vol. 101, no. 12, Article ID 123911, 2007.

[18] http://www.bam.de/de/service/publikationen/powder_cell .htm.

[19] T. Hashimoto, T. Numasawa, M. Shino, and T. Okada, "Magnetic refrigeration in the temperature range from $10 \mathrm{~K}$ to room temperature: the ferromagnetic refrigerants," Cryogenics, vol. 21, no. 11, pp. 647-653, 1981.

[20] K. A. Gschneidner and V. K. Pecharsky, "Magnetocaloric materials," Annual Review of Materials Science, vol. 30, no. 1, pp. 387429, 2000.

[21] L. Xi-Bin, Z. Shao-Ying, and S. Bao-Gen, "Magnetic properties and magnetocaloric effects of $\mathrm{Mn}_{5} \mathrm{Ge}_{3-x} \mathrm{Ga}_{x}$," Chinese Physics, vol. 13, no. 3, pp. 397-400, 2004.

[22] J. Y. Zhang, J. Luo, J. B. Li et al., "Magnetocaloric effect of $\mathrm{Gd}\left(\mathrm{Co}_{1-x} \mathrm{Mn}_{x}\right)_{2}$ compounds," Solid State Communications, vol. 143, no. 11-12, pp. 541-544, 2007. 
[23] J. Brock and M. Khan, "Large refrigeration capacities near room temperature in $\mathrm{Ni}_{2} \mathrm{Mn}_{1-x} \mathrm{Cr}_{x}$ In," Journal of Magnetism and Magnetic Materials, vol. 425, pp. 1-5, 2017.

[24] J. B. Forsyth and P. J. Brown, "The spatial distribution of magnetisation density in $\mathrm{Mn}_{5} \mathrm{Ge}_{3}$," Journal of Physics: Condensed Matter, vol. 2, no. 11, pp. 2713-2720, 1990.

[25] N. Yamada, S. Shibasaki, K. Asai, Y. Morii, and S. Funahashi, "Magnetic properties of $\left(\mathrm{Mn}_{1-x} \mathrm{TE}_{x}\right)_{5} \mathrm{Ge}_{3}$ : $(\mathrm{TE}=\mathrm{Cr}$ and $\mathrm{Fe})$," Physica B: Physics of Condensed Matter, vol. 213-214, pp. 357359, 1995.

[26] M. Khan, I. Dubenko, S. Stadler, and N. Ali, "Magnetic and structural phase transitions in Heusler type alloys Ni 2MnGalxinx," Journal of Physics Condensed Matter, vol. 16, no. 29, pp. 5259-5266, 2004.

[27] B. Arayedh, S. Kallel, N. Kallel, and O. Peña, "Influence of nonmagnetic and magnetic ions on the MagnetoCaloric properties of $\mathrm{La}_{0.7} \mathrm{Sr}_{0.3} \mathrm{Mn}_{0.9} \mathrm{M}_{0.1} \mathrm{O}_{3}$ doped in the $\mathrm{Mn}$ sites by $\mathrm{M}=\mathrm{Cr}, \mathrm{Sn}$, Ti," Journal of Magnetism and Magnetic Materials, vol. 361, pp. 68-73, 2014. 

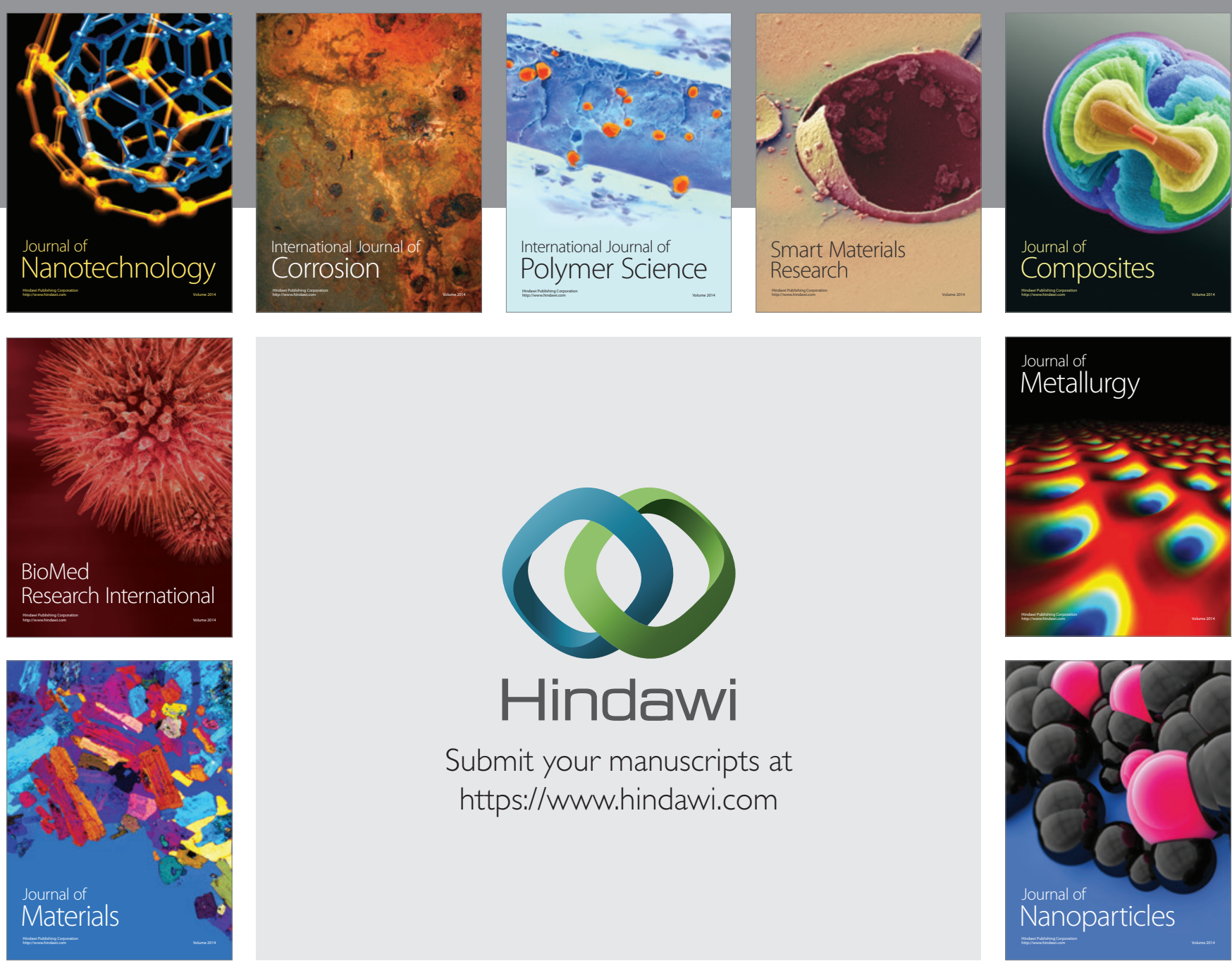

\section{Hindawi}

Submit your manuscripts at

https://www.hindawi.com

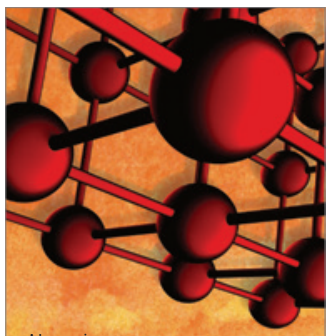

Materials Science and Engineering
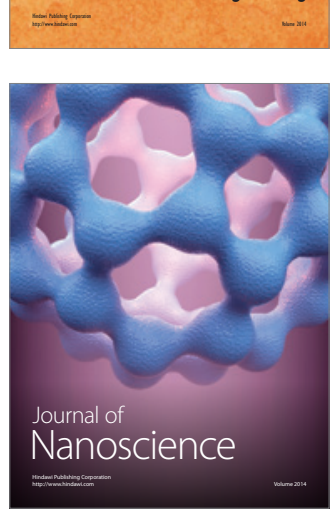
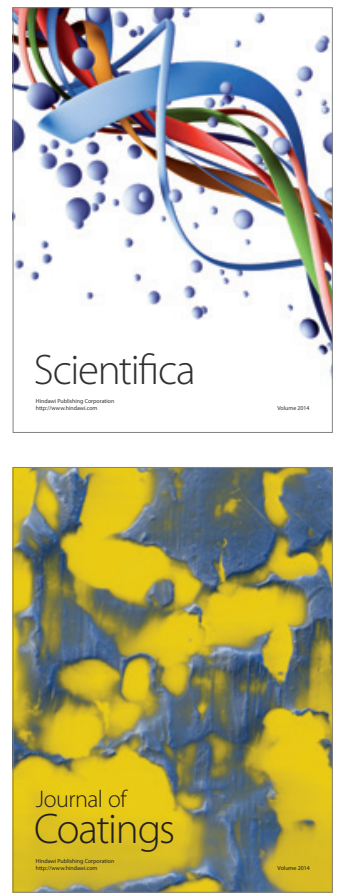
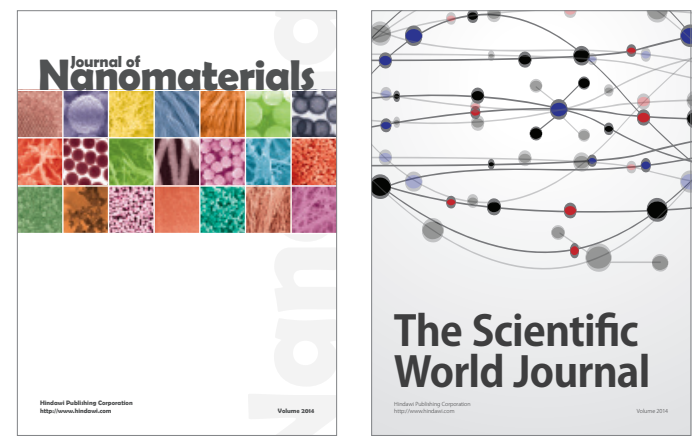

The Scientific World Journal
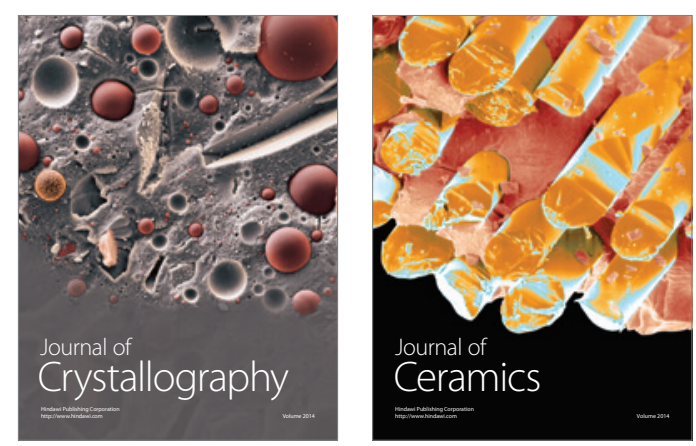
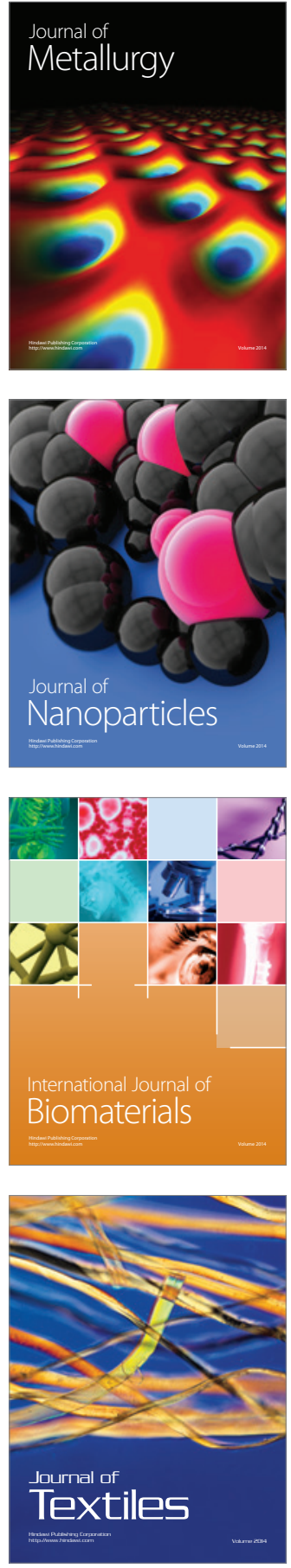